\title{
The Impact of Media on Juvenile Delinquency in the Care of Abu Dhabi and Fujairah - United Arab Emirates
}

\author{
Mufaraj Ali Al-Karbi \\ Master student, Universiti Pendidikan Sultan Idris \\ Mohammed Yousef Mai \\ Faculty of Human Development, Universiti Pendidikan Sultan Idris
}

\begin{abstract}
This study was aimed to investigate the impact of the media on juvenile delinquency in the care of Abu Dhabi and Fujairah - United Arab Emirates, as well as studying the behaviours of adolescents in watching the media and its influence on them, and also measuring the readiness of the delinquents to accept the awareness of media as a means of adjustment and a proactive means to prevent delinquency. A quantitative approach was used for this study, A questionnaire was distributed to 46 delinquent juveniles ( 39 males and 7 females) who were taken care of by Abu Dhabi and Fujairah care homes, and it was also distributed to 120 intermediate and secondary school students ( 65 males and 55 females) in Abu Dhabi and Fujairah. The findings showed that there is a positive relationship between the number of school failures in adolescents more than twice and the possibility of a teenager at risk of becoming a delinquent, the probability of juvenile delinquency and high rates for adolescents who watch different media materials. The results also showed that there is no relationship between adolescents imitating violent content in media and the phenomenon of juvenile delinquency. As a conclusion, Juvenile delinquency is more likely to be in the 15 to 17 age group.
\end{abstract}

Keywords: Juvenile Delinquency, Media, Adolescents.

\section{Introduction}

There is no doubt that children are the basis of society and the cornerstone of nations. They are the hope of the nation to build glory and establish civilizations. One of the most important threats that surround these adolescents, the community and social peace is the phenomenon of juvenile delinquency, which is a malignant phenomenon that threatens the nation and violates its rules and principles. It is very important to be investigated, to identify and determine its causes in order to be able to confront it and to prevent it from society.

No one denies that the media has a great impact on the lives of young and old people, men and women, where this impact on human behavior, clothing, appearance and personality traits. For example, the theory of cultural implantation suggests that television has become a family member; children start associating with it at an early age and play a cultural role; it provides viewers with religious, historical, geographic and other information, and this is one of the benefits and advantages of this device (Abdel Hamid, 2000).

Media is everywhere from the devices of television, radio, computer and to Internet mobile phones, video games, newspapers and magazines, primarily smartphones that they carry with them everywhere; at home, school, street, transportation and markets, which they are deeply and directly affected by. One of the most important features of this age is the rapid development of the media and communication.

However, television has undeniable negatives. Some studies have shown that many children's programs, especially cartoons, are horribly violent (Huesmann, 2007). For example, violence accounts for $42 \%$ of 'Teenage Mutant Ninja Turtles', $40 \%$ of 'Tom \& Jerry' and $24 \%$ of 'Grindizer'. The forms of violence used by cartoon characters varied: $35 \%$ quarrels, $33 \%$ pranks, $14 \%$ battles, $5 \%$ torture, and $5 \%$ threat. Children tend to imitate what they watch $81 \%$ of males and $35 \%$ of females). The fact that most research on the impact of media violence on aggressive behavior has focused on violence in 
fictional television and film and video games is not surprising given the prominence of violent content in these media and the prominence of these media in children's lives (Anderson \& Bushman, 2001).

Psychology defines delinquency as "behavior that does not conform to the norms of the group" while Sociology considers delinquency to be: "a phenomenon arising from the pressures and conflicts of each society". The delinquency of young people is one of the most pressing contemporary social problems, not only in developed countries but also in developing countries such as the UAE. It has a negative impact on victims, society, adolescents, and their families (Al Ali , 2013). In view of the keenness of the United Arab Emirates to provide social, health and psychological care for displaced and delinquent juveniles, to assist them and rehabilitate them, from the sense of social responsibility, the researcher has taken care to play a role in this effort and to put a brick in the wall in addressing this phenomenon.

In regard to Juvenile, the Psycho-sociologists refuse to define a specific age at which each stage of modernity ends. However, the scientists agreed that the individual since birth is going through different stages that are difficult to separate from their intertwining and overlapping. They have tried to bring the social psychology division of the body closer to the legal division by dividing the age of modernity into three stages: the stage of self-focus, the stage of focusing on others, the stage of social and psychological maturity, But the stages overlap between each other as the seasons of the year in the gradation and transition from one stage to another is gradual, not sudden (Zahrani, H. A., 1981). In the United Arab Emirates, according to the law of juveniles and delinquents, a juvenile is the person who did not exceed the age of 18 at the time of the act being committed or in a situation of displacement.

The social learning theory assumes that the viewer of visual media has the ability and the possibility to learn aggressive behavior through the contents and programs, and that viewing increases the likelihood of learning deviant behavior. Bandura and Walters confirm that the individual can learn and imitate the behavior of aggressive characters presented as models to follow and provide opportunities to learn aggressive behavior. This theory assumes that the viewer is likely to learn violence and act violently after watching and adopting violent content on television.

\section{Problem Statement}

Psychologists point out that the child is not born of one nature, but he acquires the characteristics of his behavior and trends from the social and physical environment that he becomes part of it by birth. In addition, Psychologists emphasize that children and adolescents are the most affected than adults by TV programs (Allawi, 2010). Since the early 1960s the results of research exposure to violence in television, movies, video games, cell phones, and on the internet certainly increases the risk of violent behavior on the viewer's part just as growing up in an environment filled with real violence increases the risk of them behaving violently (Huesmann, 2007).

A meta analytic review of the video-game research literature reveals that violent video games increase aggressive behavior in children and young adults (Anderson \& Bushman, 2001). It has become clear to the researcher that the focus of this research on certain reasons is mainly on this phenomenon, as the media is the main reason that affects directly and indirectly in all segments of society especially the children.

According to Al Ali (2013), a review of existing Arabic studies aiming to examine juvenile delinquency indicates that: (a) in the majority of Arabic countries, there has been an increase in juvenile delinquency; (b) most studies have paid attention to treatment rather than prevention; (c) most previous studies have been based on methods of document analysis; and (d) many researchers have suggested the importance of conducting further research in the field of juvenile delinquency prevention. Unfortunately, in the UAE and in many other developing countries, this issue has not been given significant attention until recently (Al Ali, 2013).

The study problem concentrates on the negative impact of media on juvenile delinquency, by exposing adolescents to scenes of violence, hatred and extremism. This is due to the fact that the various media are full of these scenes, which lead to the growing phenomenon of juvenile delinquency and the bad and ugly examples of people we see in the street and in the work who are obviously influenced by media too much; it cultivates their tendency to aggression, hatred and violence and takes the feelings of mercy and compassion from their hearts. Therefore, it is important to examine the relationship between the media and juvenile delinquency in UAE, Abu Dhabi, where adolescents are greatly affected by the scenes of violence and hatred they watch in television films, computer, internet, video games. 


\section{Research Questions}

According to the problem statement and aims, researcher fixed some research questions as followed:

What are adolescents' habits in using the media?

What kind of media material would be preferred by adolescents (normal and delinquent)?

Does watching the various media affect the behavior and attitude of juvenile delinquents?

\section{Research Methods}

A descriptive analytical method has been implemented to illustrate and diagnose the actual reality of juvenile delinquency and the impact of this phenomenon with the exposure of delinquent juveniles to media materials in Abu Dhabi.

\section{Population and research sampling}

The study population is the Schools and Juvenile Care Centres in Abu Dhabi and Fujairah. The delinquents detained in Rehabilitation Care Centres in Abu Dhabi and Fujairah were interviewed. In addition, secondary school students in Abu Dhabi and Fujairah were also interviewed, this is in terms of the study population. As for the sample of the study, the researcher chose to have the study sample in two groups:

A - A sample of delinquents detained in Care Centres in Abu Dhabi and Fujairah. They are 46, ranging from 14 to 17 years. The percentage of males in the juvenile sample was $84.78 \%$ compared to $15.22 \%$ of females.

B - A sample of a group of normal/typical adolescents from secondary school students in Abu Dhabi and Fujairah. They are 130 students aged $13-17$ years, of whom 65 were males (50\% of the total sample) and same percentage for females.

\section{Research Instrument}

The survey instrument used in this study, it is not a test instrument but it is a descriptive one. It has been developed based on literature review, observation and interviews. The questionnaire was done in two parts, the first part is the personal information data that represent the variables between the members of the two research samples, and there is a difference between the two forms for each of the research samples under this part. The second part are 13 questions of the questionnaire. These questions are identical in the forms of the two research samples. However, due to the difference in the first part of the questionnaire, two questionnaire forms were used, one for juvenile delinquents and the other for the sample of typical students of middle and secondary schools.

\section{Results}

\section{Research question 1: What are adolescents' habits in using the media}

The first question is concerning of the influence of media in adolescents and their tendency towards imitation. It is about imitating actors in actions films, violence and detective films, as well as imitating artists and celebrities in their clothes and hair styles, and also imitating of some movements or attacks seen in professional wrestling programs with friends at home, street, school or anywhere. The results are presented in figures (1,2, and 3).

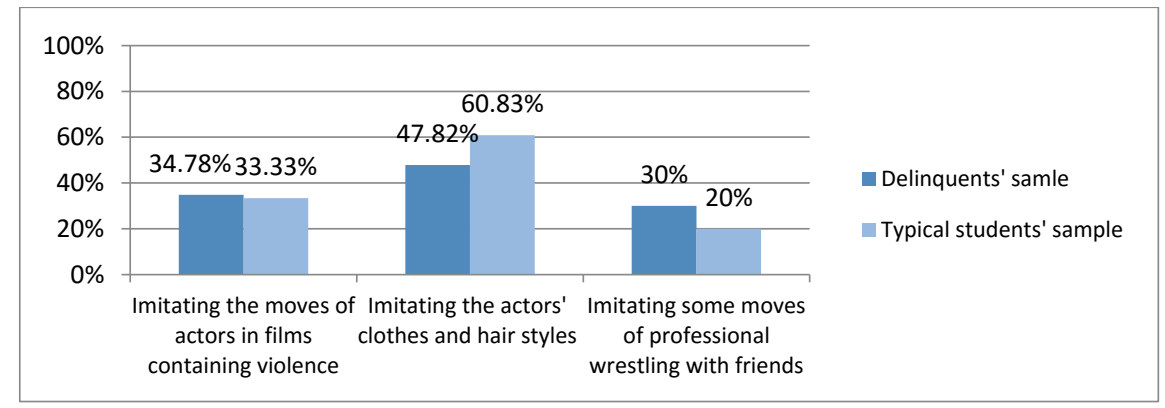

Figure (1) represents the proportions of adolescents' imitation of different media materials 
Based on figure (1), it is clear that the ratios of the imitation of adolescents to the actors' moves in violent and detective films between the two samples are close to each other, where it has reached $34.87 \%$ in the delinquents' sample and $33.33 \%$ in the typical students' sample. They are almost equal proportions and there is no indication that watching films of violence leads to violence, but these proportions confirm one of the study hypotheses that says there is a strong and significant impact of media on adolescents. The graph also shows the high proportions of adolescents' imitation of the clothing and their hair styles of artists in both samples, where it has reached $47.82 \%$ in delinquents' sample and $60.83 \%$ in typical students' sample. It seems that the sample of typical students has a higher rate of adolescents' imitation of artists and celebrities because of the large proportion of females, including up to $50 \%$ of the sample, whereas the proportion of females in the sample of delinquents is only $15.2 \%$, these proportions also confirms the study hypotheses that says there is a strong and significant impact of media on adolescents, which is represented in the Imitation of clothing and hair styles of artists and celebrities, and the ratio reaches more than $60 \%$ as in the sample of typical adolescents.

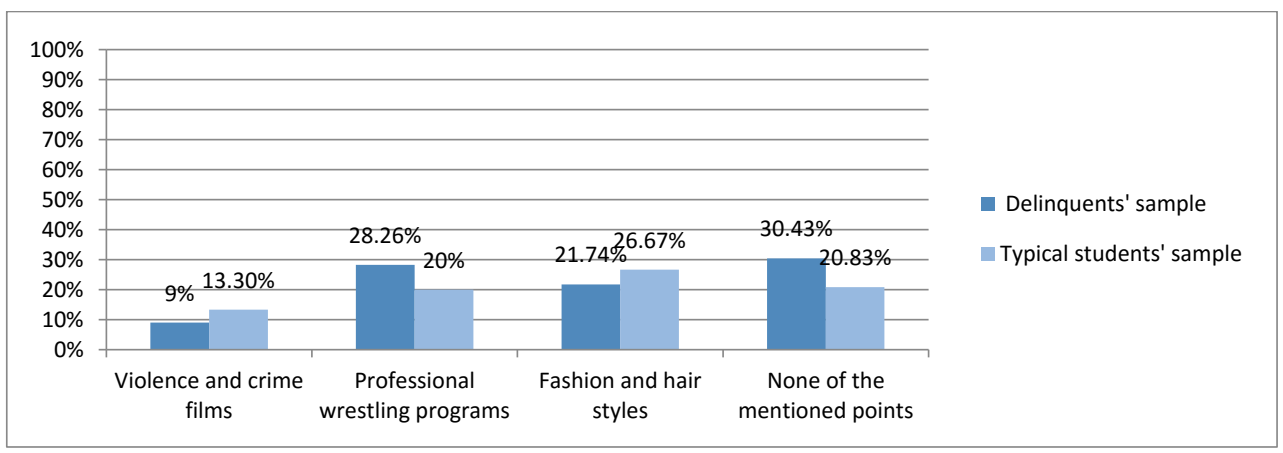

Figure (2) represents the percentage of media materials most likely being imitated by adolescents

Figure (2) illustrates the findings that is related to the first question, it shows the relationship between the proportions of the media materials that are most likely being imitated by adolescents. The highest percentage of delinquents' sample showed that they do not see that adolescents imitate any media material, which amounted to $30.43 \%$ compared to $20.83 \%$ of the typical students' sample, while the highest percentage regarding the imitation of professional wrestling episodes was in the sample of delinquents where the percentage was $28.26 \%$, compared to $20 \%$ in the sample of typical adolescents, which are unequal but there is no significant differences on which no result can be based. Also, the media material that has the largest percentage of imitation is the fashion and haircut programs, with $26.67 \%$ of the typical students' sample, compared to $21.74 \%$ for the sample of delinquents, which are close ratios. In addition, to ensure that there is no significant difference between the results of the two samples, we have added up the proportions of the imitation of media materials with violent content (wrestling, violence and crime films) for each of the two study samples separately, where the percentage was 37\% in the sample of delinquents compared to $33.33 \%$ of the sample of typical students, which is also almost an equal proportion on which no result can be based. However, this percentage shows the behavior of adolescents in general and their tendency to imitate the violent content in media by more than a third, and thus, it is a percentage to be aware of and highlighted as the imitation of violence leads to similar violence and that leads to a doubling of the ratio. If a teenager used violence with his schoolmate, he would react violently to him. 


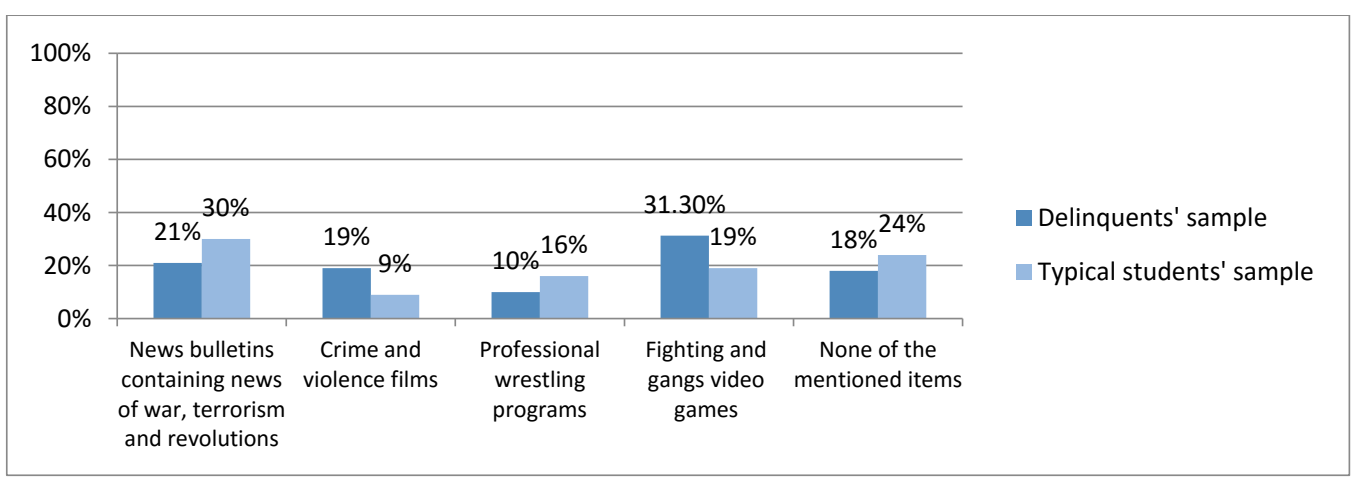

Figure (3) represents the percentage of media materials that adolescents advise others not to watch

Figure (3) shows the percentage of media materials that adolescents advise others not to watch. The highest percentages were of the news bulletins containing news of wars, terrorism and revolutions, as well as fighting and gangs video games, in both samples, where the addition of the two percentages has reached $54 \%$ in the delinquents' sample, compared to about $49 \%$ in the sample of typical adolescents. These ratios are found close to each other on which no result can be based. However, it should be noted that most of the members of both samples tend to renounce violence and hostility, which are innate traits. As figure (3) shows, $82 \%$ of the study sample of delinquents advises others not to watch violent material regardless of the image presented, compared to $75 \%$ of the study sample of typical adolescents who also advise others not to watch violent material, regardless of the image presented.

It should be pointed out here that the first hypothesis concerning the existence of a relationship between the imitation of scenes of violence and the rates of juvenile delinquency phenomenon is not proven.

RQ2: What media are adolescents interested in, and what kind of media material would be preferred by delinquent adolescents?

This question asks about the most activities carried out by the adolescent during his free time. The responses included of different media means and some other activities to measure the extent of adolescents' attachment to the various media without any other activities in their free time. And to bring the scene closer to the mind, we have made a graphic illustration of the spending of leisure-time question between the samples of delinquents and the typical adolescents, as shown in the following Figure (4-7):

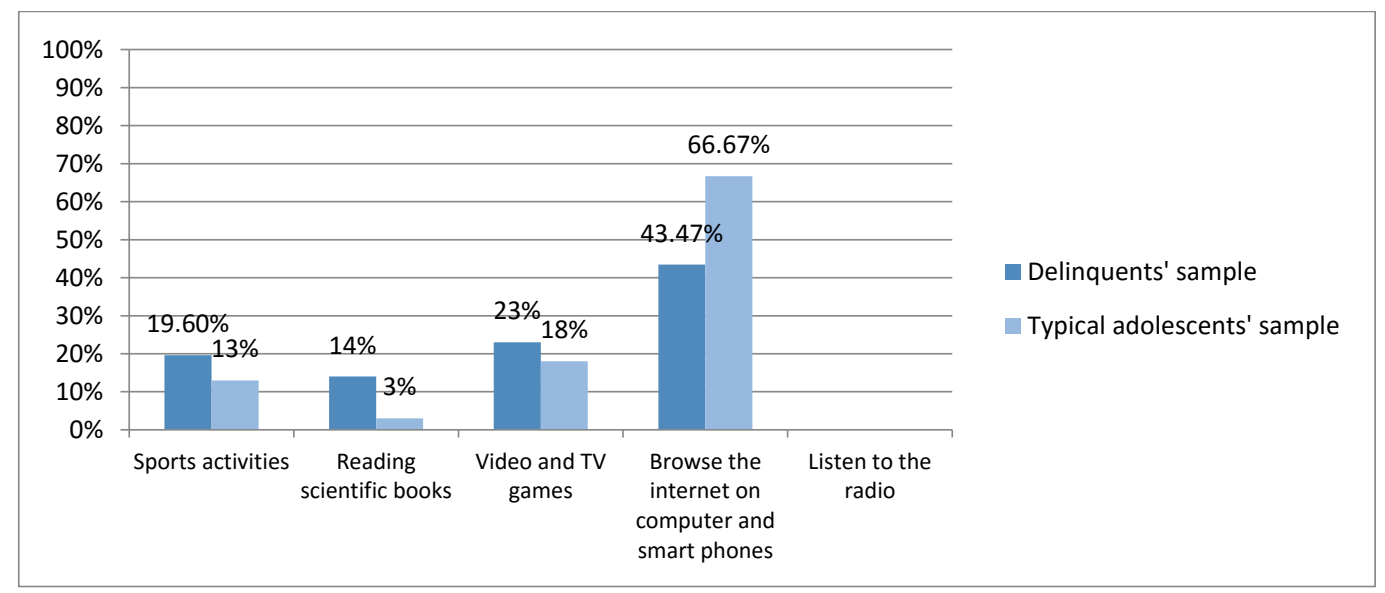

Figure (4) represents the percentages of adolescents spending their leisure time depending on different activities 
Figure (4) represents the percentage of adolescents of both samples who spend their leisure time in media materials or other activities, we can observe the high percentage of adolescents spending their free time in modern media, namely computer, internet, smart phones and other social networking sites and apps, such as Facebook, Twitter, Instagram, Whats App, ...etc.. This percentage constitutes the majority in both samples, where it has reached $43.47 \%$ in the sample of delinquents, and $66.67 \%$ in the sample of typical adolescents.

These percentages show the dominance of the modern media over the traditional media, such as television, newspapers, magazines, radio and video games. For example, the total of the traditional media ratios in the sample of delinquents equals to $37 \%$, which is less than the percentage of modern media viewing in the same sample $(43.47 \%)$. The result is more evident in the sample of typical adolescents, where the total of the traditional media ratios equals to about $21 \%$, which is less than twice of the percentage of modern media viewing in the same sample $(66.67 \%)$. The results also show low percentages of adolescents who spend their free time playing sports, reaching about $19.56 \%$ in the delinquents' sample, compared to $12.5 \%$ in the sample of typical adolescents. It has also been shown that the media have a plentiful luck on which adolescents like to spend their free time.

The researcher attributed the reasons for the control of media in general and modern media in particular to the teenagers' leisure time, is because it is easy to watch media materials due to the availability of gadgets all the time, as there is at least one or more televisions in a house, one or more computers, every teenager, and every individual in the community owns a personal smartphone, and also Internet access has become possible at home, school, street and everywhere, and social networking sites compete to win more followers, as well as technical programs, contests, news, music and video games.

The following are the results regarding the adolescents' behavior in watching media materials and using their preferred gadgets, and the place of these gadgets during their free time instead of other various activities. This question was asked about the number of hours that teenagers spent in watching different media materials per day, these results of the answer to this question are presented in figure (5) below:

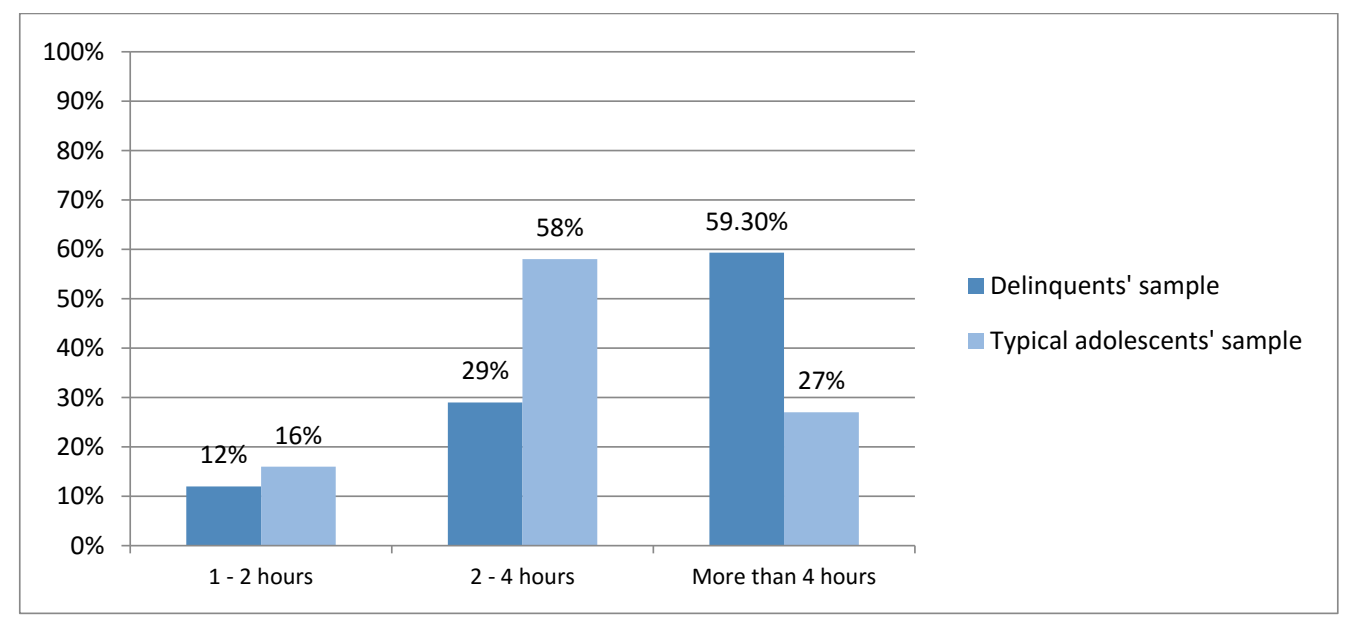

Figure (5) shows the percentages of number of hours adolescents spend in watching different media materials (per day)

Figure (5) shows the percentage of watching hours that are more than 4 hours per day in the sample of delinquents, and it is higher than that of the sample of typical adolescents, where it has reached $58.69 \%$ In the delinquent sample, compared to $26.67 \%$ in the typical adolescents' sample, which indicates that the percentage of delinquents is twice as high as the percentage of typical adolescents. This confirms the serious danger of the control of media gadgets and materials on the free time of adolescents as the results indicate the increased probability of a teenager falling in delinquency with the increase in the number of hours spent in watching media materials, especially over four hours a day. The researcher attributed this to the fact that the increase in the rates of watching media materials over four hours a day has more than an effect on adolescents, including: 
the more the number of watching hours, the more of violence content of media material might be watched, such as detective films, crime \& violence films and even pornographic films, as well as the news of killings, wars, bombings, revolutions and assassinations. So, the quantitative content received by teenagers in this case is much greater than those who have fewer rates of watching hours.

The increase in the number of watching hours indicates the absence of the role of family control which will be explained further in the family control question (Question 4), which increases the chances of deviation and crime.

More number of watching hours leads to fewer hours of study with a lack of concentration in the study hours and this leads to a low sense of responsibility and increase the probability of academic failure rate, which in turn is related to the phenomenon of delinquency by a certain amount as we have shown in the overall results of this chapter, academic failure may lead to crime and crime may Lead to academic failure and possibly dropout from school and education.

On the one hand, the differences above are between the two samples. However, on the other hand, if the percentages of watching from 2 to 4 hours and watching of more than four hours are added together for each sample separately, we will find that the final percentages are almost equal, where it equals to about $87 \%$ in the delinquents' sample, and $83.5 \%$ in the sample of typical adolescents, and they are very high rates and considered dangerous indicators of the increase and intensity of the hours teenagers spend in watching media materials every day,

The following are the results regarding the adolescents' behavior in watching media materials and their preferred means, and the place of gadgets during their free time versus other various activities.

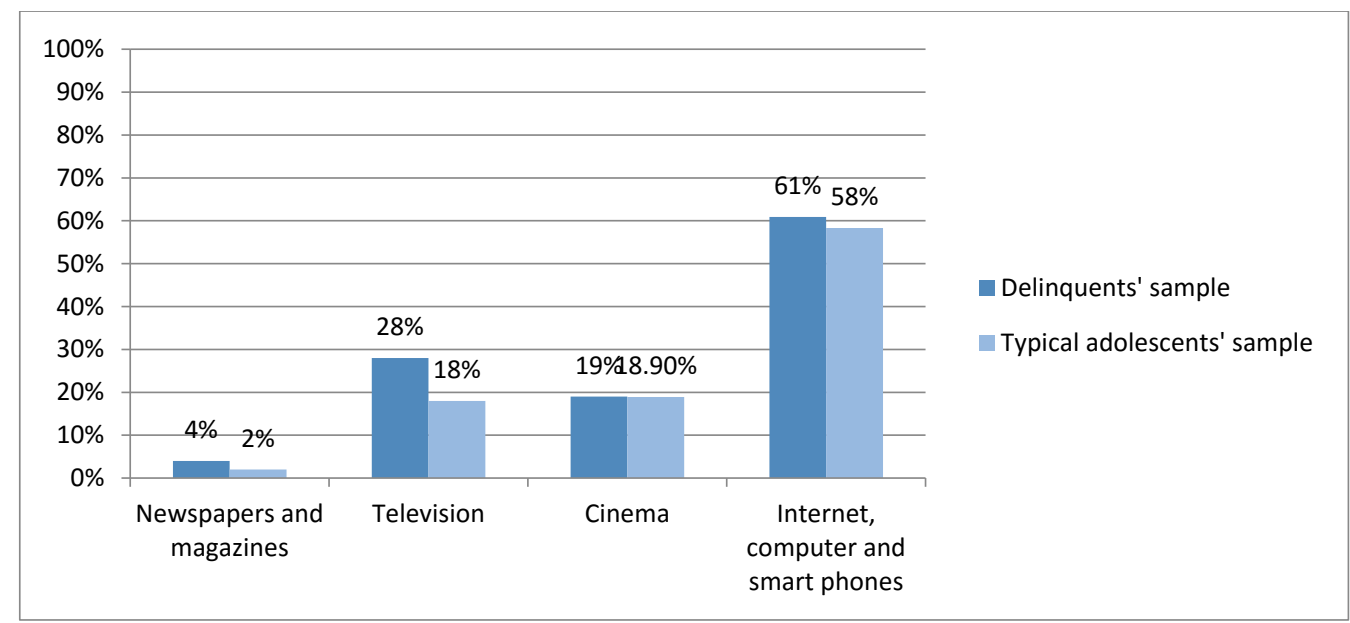

Figure (6) represents adolescents' habits in their favourite media

By checking the results related to the adolescents' behaviour in watching different media and their favourite means. A high percentage was found in both samples of adolescents who prefer computers, smart phones and the Internet as a means of watching media materials, where the percentage has reached $60.87 \%$ in the sample of delinquents, and $58.33 \%$ In the sample of typical adolescents, and they are high percentages as we have shown and explained before, so no need to repeat the reasons here again. It can be observed from figure (6) above that there are no differences between the ratios of the two study samples at any point, and this indicates that there is no evidence in this graph on which the research can be based.

The following is the results about the adolescents' behavior in watching media and their preferred materials, and the place of the gadgets during their spare time in exchange for other activities. 


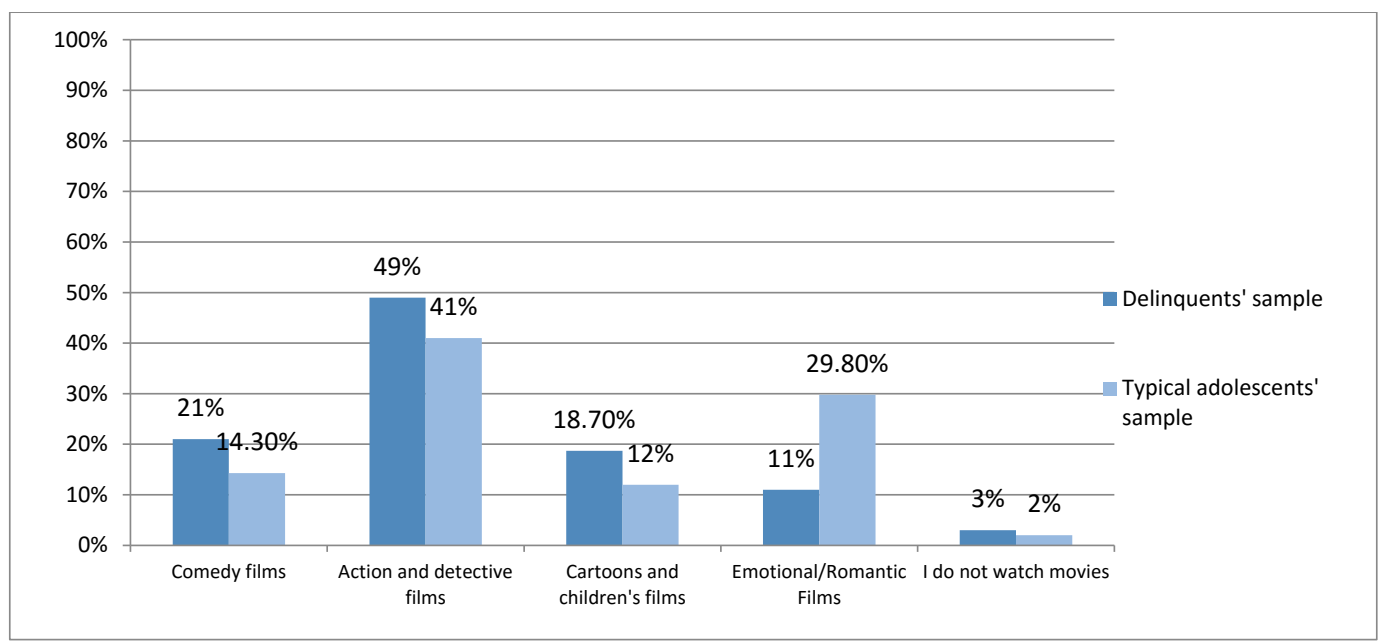

Figure (7) represents adolescents' favorite type of TV movies

Figure (7) show that the adolescents' behavior in watching media and their preferred means, and the place of these means during their spare time versus various other activities, which asks about the favorite movie type of adolescents, and it is represented in figure (7), the percentages of preference for watching detective and crime films are the highest in both samples, where it has reached $47.82 \%$ in the sample of delinquents, and $40.83 \%$ in the sample of typical adolescents, although the ratios are close, but the difference between them is small on which no result can be built or based. Thus, there is no correlation between the phenomenon of delinquency and watching movies with violent and hostile content has not been proven. Therefore, the fourth hypothesis, which states that there is a relationship between juvenile delinquency and the media containing scenes of violence, fighting and hatred, is not proven.

It was found that there is no correlation between delinquency and the habits of spending leisure time on watching various media materials, but the results of the analysis prove the hypothesis that states adolescents spend most of their free time on the various media without any other activities.

The results did not prove the second hypothesis, which states that there is a correlation between juvenile delinquency and the media containing scenes of violence, fighting and hatred.

\section{RQ3: Does watching the various media affect people's behavior, especially teenagers?}

The following is analysis of the results of question (3) regarding the question of parents' follow-up to their children and asking them about the type and number of hours they spend in watching various media materials. The question is about whether one or both parents asked you about the number of hours you spent in watching television or practiced video games and browsing the internet. As presented in Figure ( 8 and 9$)$ below: 


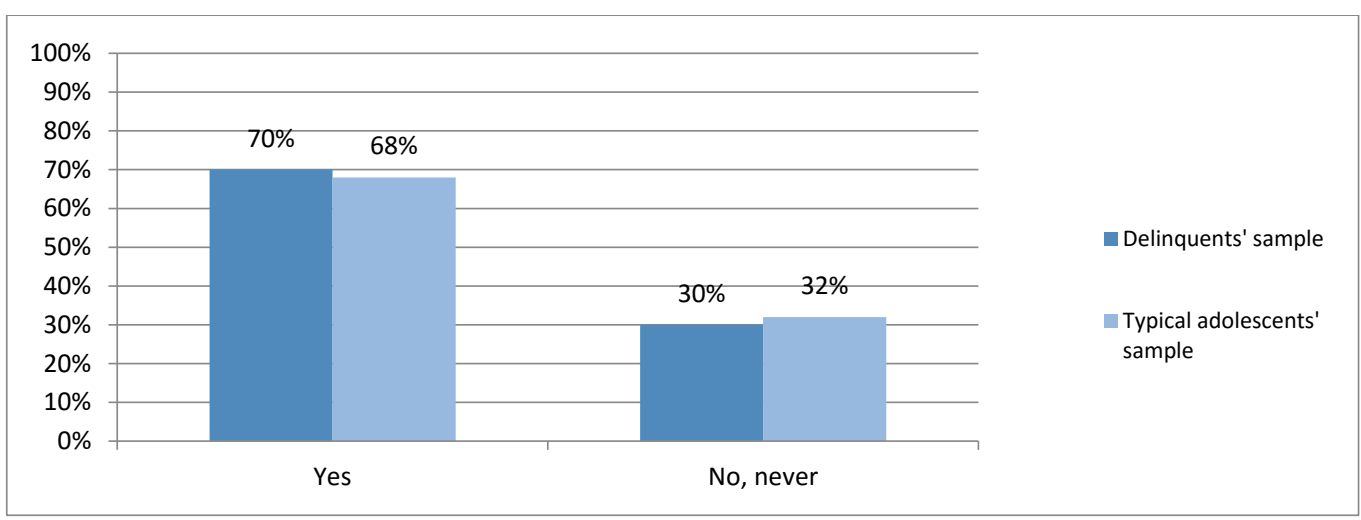

Figure (8) shows the parents' follow-up rates for the number of hours spent by their children in watching media materials

Figure (8) shows the analysis of the results of question taht asks whether one or both parents ask you how many hours you spend in watching TV or practice video games and browse the internet. It is found that the percentage of parents who follow up their children is estimated to be at least two thirds of the study samples of both juveniles and typical adolescents, where the percentage of delinquents was $69.56 \%$, compared to $65.83 \%$ in the sample of typical adolescents, and they are close ratios with no significant difference on which a result can be based. Based on the convergence of ratios between the two samples as shown in the graph above, we conclude that the sixth hypothesis, which states that there is a relationship between watching various media with the absence of family control of adolescents, and the phenomenon of delinquency, is not proven.

The following is an analysis of the results regarding if parents' follow-up to their children and asking them about the type and number of hours they spend in watching different media materials, which asks about whether one or both parents ask them about the type of the films they watch on television or the internet and about the video games they play. As presented in Figure (9) below:

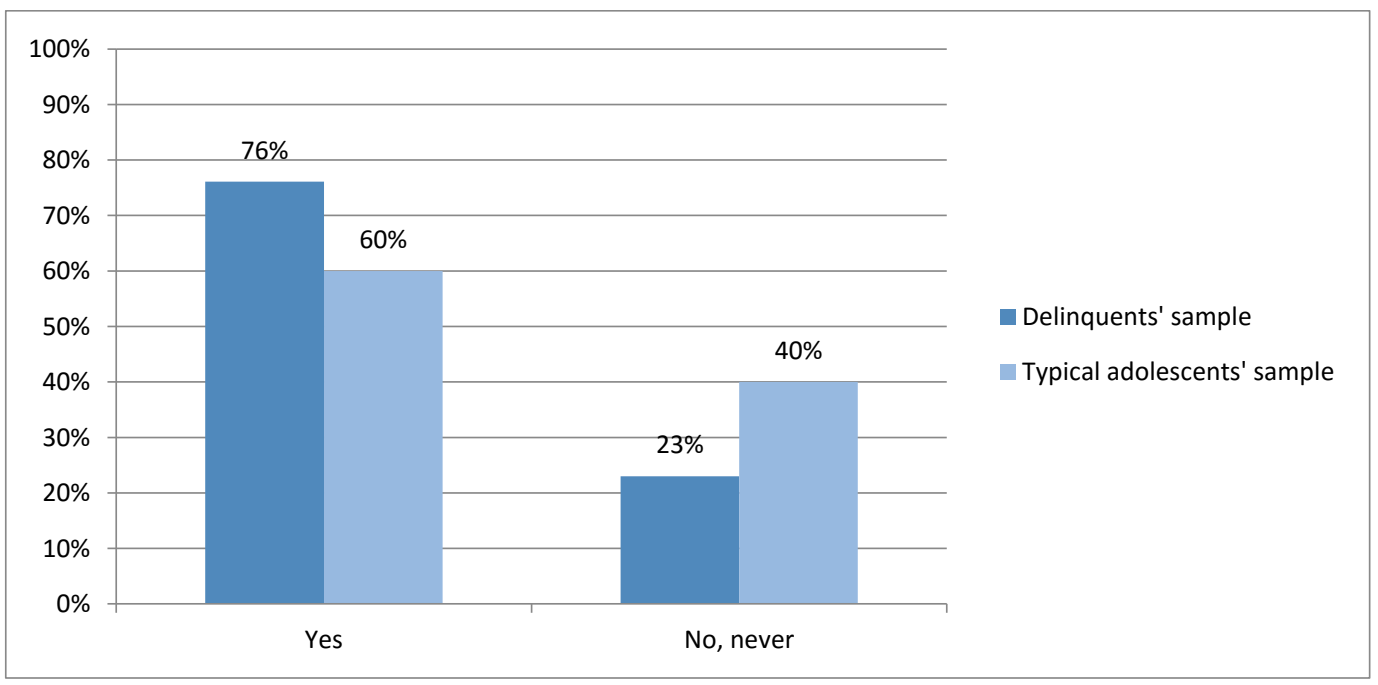

Figure (9) shows the rates of parents' follow-up to the media materials watched by their children (members of the samples)

Figure (9) shows the percentage of parents who follow up their children is high by about two thirds of both study samples, where it has reached $76.09 \%$ in the sample of delinquents, compared to $60 \%$ in the sample of typical adolescents. These 
ratios are close, and thus, there is no significant difference between them on which a result can be based. As a result of this convergence of ratios, we conclude that the sixth hypothesis, which states that there is a relationship between watching various media materials with the absence of parents' control and the phenomenon of delinquency, is not proven.

What we would like to point out here is the presence of about one-third of both samples (the delinquents and typical adolescents) are from parents who do not ask them about the number of hours they spend in watching various media materials. Similarly, about one-third of both samples (the delinquents and typical adolescents) are from parents who do not ask them about the type of media materials that they watch.

This is the case of almost one-third of all juvenile and delinquent parents who do not ask any of their children about the number of hours they spend in front of the various media, as well as about a third of each of the juvenile and delinquent parents None of them asks their children about the quality of the media they are watching.

The third hypothesis, which states that there is a relationship between watching different media materials with the absence of family supervision/control of adolescents, and the phenomenon of delinquency, is not proven.

\section{Conclusion}

1. The results showed that there is no relationship between adolescents' viewing of media materials with violent content and the phenomenon of juvenile delinquency. This is due to the convergence of viewing rates between both study samples.

2. There is a positive relationship between the probability of juvenile delinquency and the high rates of adolescents' watching different media materials (more than 4 hours).

3. The correlation between imitating violence scenes presented in media and juvenile delinquency phenomenon is not proven.

4. The results showed high rates of adolescents' response to awareness materials in the media at the centres of preservation and rehabilitation.

5. Television and Friday sermons are found the most media that adolescents accept awareness through them.

6. Teenagers spend most of their time in different media, and we noted the dominance of the modern media on adolescents, not the old media.

7. The hypothesis which states that 'there is a relationship between watching various media with the absence of family control and supervision on adolescents, and the phenomenon of delinquency', is not proven.

8. The importance of focusing on religious speech to raise adolescents' awareness, where many members of the study sample - up to two-thirds - of each of the delinquents and typical adolescents samples were found keen to attend Friday sermon every week.

9. There is a positive relationship between the number of adolescents' academic failures in school for more than twice and the probability of a teenager to fall at the risk of delinquency.

10. The risk of juvenile delinquency increases in the age group of 15 to 17 years, where delinquents at this age group account for more than two-thirds of the total number of delinquents in the sample. Therefore, the age group between the ages of 15 and 17 is the most dangerous age group of adolescence.

11. The percentage of male delinquents is greater than that of females, where $85 \%$ of delinquents were males compared to $15 \%$ of females.

\section{References}

[1] Abdul Hamid, Anani Hanan (2000), Child, Family and Society, Dar Safa, Amman, p.26

[2] Al Ali, Mohamed (2013). Towards Effective Juvenile Delinquency Prevention Strategies and Policies in Abu Dhabi Police: An Investigation of Critical Factors. A thesis submitted to the University of Stirling for the degree of $\mathrm{PhD}$ in the School of Law.

[3] Al-Ali, Al-S. S. (1988). The Net Dictionary in the Arabic language, Riyadh.

[4] Allawi, Rafik Ahmed (2010), TV between the pros and cons, security and life Issue (349) Jumada II, 1432 
[5] Anderson, C. A., \& Bushman, B. J. (2001). Effects of violent video games on aggressive behavior, aggressive cognition, aggressive affect, physiological arousal, and prosocial behavior: A meta-analytic review of the scientific literature. Psychological Science,12, 353-359

[6] Hosseini, H. (1995). Our Sons in Danger. First Edition.

[7] Huesmann, L. Rowell (2007). The Impact of Electronic Media Violence: Scientific Theory and Research. Journal of Adolescent Health 41 (2007) S6-S13.

[8] Zahrani, H. A. (1981). Psychology of Growth. Dar Al-Awda, Beirut. 